\title{
Design of Microstrip Array Antenna for Wireless Communication Application
}

\author{
Hassan Elesawy, W. Swelam, Abdalmonem Fouda, Ismail M. Hafez \\ 1,2(Electronics and Comm. ,Faculty of Engineering,Ain Shams University, Cairo,Egypt, 3(Communication, \\ Faculty of Engineering, Modern Academy, Cairo, Egypt, \\ 4(Chairman of Communication, Faculty of Engineering, Ain Shams University, Cairo, Egypt,
}

\begin{abstract}
In the recent years the development in Wireless systems requires the development of low cost, minimal weight and low profile antennas that are capable of maintaining high performance over a wide spectrum of frequencies. This technological trend has focused much effort into the design of a microstrip patch antenna. The objective of this paper is to design, and fabricate a fed rectangular microstrip patch antenna (EShape). The operating frequencies of antenna are from $1.85 \mathrm{GHz}$ to $1.99 \mathrm{GHz}$, which governs the resonant frequency $1.9 \mathrm{GHz}$ of the antenna. Two parallel slots are cut to perturb the surface current path that is corporate into the patch to expand its bandwidth. Initially we set our antenna as a single patch and after evaluating the outcomes of antenna features; operation frequency, radiation patterns, reflected loss, efficiency and antenna gain, we transformed it to a $1 \times 2$ linear array. Finally, we analyzed the $1 \times 4$ corporate feed linear microstrip patch array antenna that has been designed with dielectric constants of $\boldsymbol{\varepsilon}_{\mathrm{r}}=2.2$ with fixed substrate height of $\mathrm{h}=1.5748 \mathrm{~mm}$ (substrate RT/ Duroid 5880).
\end{abstract}

Keywords: - Microstrip patch antenna, $1.9 \mathrm{GHz}$, single patch antenna, $1 \times 2$ linear array antenna, $1 \times 4$ linear array antenna and antenna gain.

\section{INTRODUCTION}

Wireless communication has become an integral part for modern world the most popular standard for mobile phones in today's world is CDMA. The wireless providers use individual radio frequencies multiple times by dividing a service area into separate geographical zones, or cells, each cell requires its own radio transmitter/receiver antenna. CDMA systems operate in different frequency ranges in different countries around the world. Most CDMA systems operate in the $1850 \mathrm{MHz}$ to $1990 \mathrm{MHz}$ frequency bands in world [1]. Microstrip patch antenna is promising to be a good candidate for the future technology. Microstrip patch antenna consists of a dielectric substrate, with a ground plane on the other side. Due to its advantages such as low weight [1], low profile planar configuration, low fabrication costs and capability to integrate with microwave integrated circuits technology [2], the microstrip patch antenna is very well suited for applications such as wireless communications system, cellular phones, pagers, Radar systems and satellite communications systems. Although patch antenna has numerous advantages, it has also some drawbacks such as restricted bandwidth, low gain, excitation of surface waves and a potential decrease in radiation pattern [3]. L-slot patch antenna [4], annular slot antenna, double patch antenna, E-shaped patch antenna[3], and feeding techniques like L-probe feed [5], circular coaxial probe feed, proximty coupled feed [6,7] are used to enhance bandwidth of microstrip patch antenna.

The bandwidth can be increased by adding loss elements but it affects efficiency of the antenna. So the better method is to use array antenna. In this design of rectangular (E-Shape) microstrip array antenna for CDMA applications, the transmitter antenna array is expected to operate within $1850 \mathrm{MHZ}-1910 \mathrm{MHz}$ with center frequency $1880 \mathrm{MHz}$, bandwidth $60 \mathrm{MHz}$ and receiver array antenna within $1930 \mathrm{MHZ}-1990 \mathrm{MHz}$ with center frequency $1960 \mathrm{MHz}$, bandwidth $60 \mathrm{MHz}$ This antenna array is fabricated in RT/D 5880 substrate.

Antenna Array: Microstrip antennas are very versatile and are used, among other things, to synthesize a required pattern that cannot be achieved with a single element. In addition, they are used to scan the beam of an antenna system, increase the directivity, and perform various other functions which would be difficult with any one single element. The elements can be fed by a single line or by multiple lines in a feed network arrangement, so in this paper we used an array to develop the performance of this antenna. One of the essential parameters for the design of a rectangular Microstrip patch antenna (E-Shape) is the Frequency of operation $\left(f_{0}\right)$ is $1.9 \mathrm{GHz}$. In our work, we initially selected the value of the substrate. Then, we evaluated the length, the width, the input impedance of the patch and the nested fed dimensions. After that, we changed the dimensions to get better performance of the antenna, i.e. radiation patterns, reflected loss, efficiency and antenna gain by simulating it using electromagnetic simulator IE3D $[5,8]$. 
The main goal of this paper is to design with a performance analysis of a corporate microstrip line feed $1 \mathrm{x} 4$ array rectangular (E-Shape) microstrip patch antennas and as well as improvement of bandwidth.

The next section describes the physical parameters of antenna and the idea of operation. Section III covers the simulation process and results analysis. Section IV shows the conclusion.

\section{PHYSICAL PARAMETERS OF ANTENNA}

Some important antenna parameters can be calculated by the transmission line method [8-10] and is explained to ease our design process, this model is written in Matlab script and the results of each parameter are shown in table 1 below [11]. The three essential parameters for the design of a rectangular Microstrip Patch Antenna are: Frequency of center operation $\left(\mathrm{f}_{0}=1.9 \mathrm{GHz}\right),\left(\varepsilon_{\mathrm{r}}=2.2\right)$ and $(\mathrm{h}=1.5748 \mathrm{~mm})$. Calculating the wavelength $(\lambda)$, since $\mathrm{C}=3 \times 108 \mathrm{~m} / \mathrm{s}$ so $\lambda=C / \mathrm{f}_{\circ}=116 \mathrm{~mm}$.[11]

\section{A. Width of the Patch (w)}

Numerically, the width of the microstrip patch can be calculated using the equation as [10]

B. Length of the Patch $(\mathrm{L})$

$$
\mathrm{w}=\mathrm{c} / 2 \mathrm{f} \circ \sqrt{\left(\varepsilon_{\mathrm{r}}+1\right) / 2}=62.4 \mathrm{~mm}
$$

The length of the patch can be calculated only if the effective dielectric constant is known [9], and the effective dielectric constant can be calculated as

$\varepsilon_{\text {eff }}=0.5\left(\varepsilon_{\mathrm{r}}+1\right)+0.5\left(\varepsilon_{\mathrm{r}}-1\right)[1+12 \mathrm{~h} / \mathrm{w}]^{-\frac{1}{2}}=2.285$

The effective length is: $\mathrm{L}_{\text {eff }}=\mathrm{C} /\left(2 \mathrm{f} \cdot \sqrt{\varepsilon_{\text {eff }}}\right)=52.23 \mathrm{~mm}$;

The length extension is:

$\Delta \mathrm{L}=(0.412 \mathrm{~h})\left(\varepsilon_{\mathrm{eff}}+0.3\right) *((\mathrm{~W} / \mathrm{h})+0.264) /\left(\varepsilon_{\mathrm{eff}}-0.258\right) *((\mathrm{~W} / \mathrm{h})+0.8)=0.816 \mathrm{~mm}$

$\mathrm{L}=\mathrm{L}_{\text {eff }}-2 \Delta \mathrm{L}=50.6 \mathrm{~mm}$

\section{Input Impedance}

The input impedance can be obtained by the equation [12]; $\quad \mathrm{X}_{\mathrm{f}}=\mathrm{L} / \sqrt{\varepsilon_{\mathrm{eff}}}=33.7 \mathrm{~mm}$

Where $\mathrm{X}_{\mathrm{f}}$ is the desired input impedance of the coaxial cable and $\varepsilon_{\text {eff }}$ is the effective dielectric constant.

Similarly, the admittance can be found using the equation.

$\mathrm{Y}_{\mathrm{f}}=0.5 \mathrm{~W}=31.2 \mathrm{~mm}$

\section{Ground Dimension}

For practical design, it is necessary to have some finite ground plane. For optimum design of small patch antenna, it is required that the ground plane should be greater than the patch dimensions by approximately six times the substrate thickness all around the fringe $[9,13]$. Hence, the ground plane dimensions $\left(\mathrm{L}_{\mathrm{g}} \mathrm{x} \mathrm{w}_{\mathrm{g}} \mathrm{xh} \mathrm{h}_{0}\right)$ would be given as:

$\mathrm{L}_{\mathrm{g}}=6 \mathrm{~h}+\mathrm{L}=59.6 \approx 60 \mathrm{~mm}, \mathrm{w}_{\mathrm{g}}=6 \mathrm{~h}+\mathrm{w}=71.8 \approx 72 \mathrm{~mm} ; \mathrm{h}_{0}=1 \mathrm{~mm}$

The above quoted physical parameter equations for antenna design is used to set the input parameters of the microstrip patch antenna. We simulate the antenna by varying the number of microstrip patches and the effect was observed on the directivity and radiation pattern.

Table 1: Optimize Parameters for E-Shaped Patch single Antenna, 1x2 and 1x4Array.

\begin{tabular}{l|c|l|l|l|l}
\hline \hline $\begin{array}{c}\text { Substrate } \\
\text { (RT/D 5880) }\end{array}$ & $\begin{array}{c}\text { Rectangular } \\
\text { patch }(\mathrm{L}, \mathrm{w}) \\
\mathrm{mm}\end{array}$ & $\begin{array}{c}\text { Slots parameters } \\
\left(\mathrm{L}_{1}, \mathrm{w}_{1}, \mathrm{~L}_{2}, \mathrm{w}_{2}\right) \mathrm{mm}\end{array}$ & $\begin{array}{c}\text { Ground } \\
\mathrm{L}_{\mathrm{g}}, \mathrm{w}_{\mathrm{g}} \\
\mathrm{h}_{0}=1 \mathrm{~mm}\end{array}$ & Feeding & \multicolumn{1}{c}{$\begin{array}{c}\text { inter-element } \\
\text { spacing }\end{array}$} \\
Single & $62.4 ; 54.6$ & $25,11-31,9.2$ & $70,65.3$ & \\
1 X2 array & $62.4 ; 54.6$ & $25,11-31,9.2$ & 150,80 & corporate- & 13.6 \\
$1 \mathrm{X} 4$ array & $62.4 ; 54.6$ & $25,11-31,9.2$ & 335,125 & feed array & 13.6 \\
\hline \hline
\end{tabular}

\section{2-1 Design of Array Antenna}

It is a known fact that changes in current distribution maneuvers the radiation pattern in case of arrays. In order to analyze the affect of current distribution on arrays, E-shaped microstrip antenna arrays consisting to two and four elements are designed at the specified frequency. The most critical aspect of designing antenna array is the inter-element spacing, the spacing can be between $0.2 \lambda$ to $\lambda$; but after rigorous simulations, it is observed that the results are best when the inter-element spacing is set to be $13.6 \mathrm{~mm}$. The feeding network of all the designed arrays consists of corporate feeding technique with quarter wave transformers and the patch used in building arrays has the same dimensions as that of a single E-shaped patch antenna [12,14]. In order to make the design clear all the specifications of designed antenna arrays are listed in Table 1. 


\subsection{1. single Element Antenna}

The geometry of proposed antenna is shown in figure 1. The design consists of $\mathrm{E}$ patch and a rectangular radiator. The structure is mounted on $70 \times 65.3 \mathrm{~mm}$ ground plane. Patch antenna, radiator and ground plane are made of $17 \mu \mathrm{m}$ thick copper sheet. The antenna is coaxial fed where the location of the Edge on the E patch is shown in figure 1a. The dimensions of the antenna are given in Table 1and the shaped single antenna is shown in Fig. 1.a.

\subsubsection{1x 2 Array Antennas}

The designed two element antenna arrays consists of two E-shaped patches of similar dimensions as that of single E-shaped antenna with corporate feeding technique and have quarter wave transformers for impedance matching. The input impedance of the feeding network is of $50 \Omega$ and SMA connector of same impedance is used. All the necessary dimensions of two element array is listed in Table 1 and the shaped 1x2 arrays is shown in Fig. 1.b

\subsubsection{1x 4 Array Antennas}

The designed four element array consists of four E- shaped patches configured in the form of an array. The same feeding technique of corporate feed with transformers for impedance matching, SMA connector of $50 \Omega$ and inter-element spacing of $13.6 \mathrm{~mm}$ is used for designing the array. All the dimensions are listed in Table 1and the shaped 1x4 arrays is shown in Fig 1.c.

\section{RESULT AND DISCUSSIONS}

The performance of the antenna has been investigated by varying the number of microstrip elements in the antenna array. In this paper, we have shown the results for a single, $1 \times 2$, and 1 x 4 antenna array elements and the effect on the gain, directivity and scattering pattern is observed.

The proposed antenna element is analyzed using the full-wave method of moment (MoM) technique with the aid of the zeland-IE3D full-wave electromagnetic simulator [5]. to calculate return loss, VSWR, impedance bandwidth, Current distribution and gains.

Fig. (2) Shows the simulated return loss (S11) parameter is better than -10dB within the frequency range of (1.84 -2.05) GHz, which means $11 \%$ band-width enhancement

$$
B W=\frac{\left(f_{L-} f_{H}\right)}{f_{C}} X 100
$$

Fig 3 shows the graph of VSWR. The minimum value of VSWR of a single, $2 \times 1$ and $4 \times 1$ antenna arrays is about 1.15, 1.2, 1.6 at $1.9 \mathrm{GHz}$. The value of VSWR should be less than 2 for desirable communication.

Fig.4 Shows the simulated Directivity of the proposed patch antenna at various frequencies is shown in the figure, the maximum achievable Directivity of a single, $2 \mathrm{x} 1$ and $4 \mathrm{x} 1$ antenna arrays is $7 \mathrm{dBi}, 9 \mathrm{dBi}, 12 \mathrm{dBi}$ at the frequency of $1.9 \mathrm{GHz}$ and the gain variation is one $\mathrm{dBi}$ between the frequency ranges of $1.85 \mathrm{GHz}$ to $1.99 \mathrm{GHz}$. Fig. 5 Shows the simulated gain of the proposed patch antenna at various frequencies is shown in the figure, the maximum achievable gain of a single, $2 \times 1$ and $4 \times 1$ antenna arrays is $5 \mathrm{dBi}, 7.5 \mathrm{dBi}, 11 \mathrm{dBi}$ at the frequency of $1.9 \mathrm{GHz}$ and the gain variation is $2 \mathrm{dBi}$ between the frequency ranges of $1.85 \mathrm{GHz}$ to $1.99 \mathrm{GHz}$.

Fig 6 shows the antenna and radiation efficiency. The maximum radiation efficiency is occurred $80 \%$ and maximum antenna efficiency is obtained about $77 \%$.

Fig $7 \& 8$ shows the $3 \mathrm{D}$ and $2 \mathrm{D}$ radiation pattern view of proposed antenna of a single, $2 \times 1$ and $4 \times 1$ antenna arrays.

\section{TESTING AND VALIDATION}

In this paper we tested our design by using electromagnetic simulator (IE3D). This is an integral equation, method of moment, full-wave electromagnetic simulator. It includes layout editor, electromagnetic simulator, schematic editor and circuit simulator, near field calculation program, format converter, current and field display program. IE3D employs a 3D non-uniform triangular and rectangular mixed meshing scheme. It solves the current distribution, slot-field distribution, network s-parameters, and radiation patterns, near field on an arbitrarily shaped and oriented 3D metallic structure in a multi-layered dielectric environment. Simulation Output of $1 \times 2$ and $1 \times 4$ arrays antenna: After finishing our design for $1 \times 2$ and $1 \times 4$ arrays antenna, we tested it by IE3D. We obtained Figures: 2, 3, 4,5,6,7 and 8. The summary of outcomes is shown below in Table 2. [5]

\section{CONCLUSION}

Three different configurations of microstrip were designed based patch antennas by setting the input operating frequency of CDMA systems devices, i. e. $1.9 \mathrm{GHz}$. The directive gain of a a single, 1x 2 and $1 \times 4$ arrays antenna is observed to be $5 \mathrm{~dB}, 7 \mathrm{~dB}$ and $12 \mathrm{~dB}$. The results showed that $1 \mathrm{x} 4$ rectangular microstrip antenna array can work as an efficient microstrip antenna as it shows improved BW efficiency, directivity, gain 
and radiation pattern. Moreover the patch area is very small as compared to conventional antenna and the directivity is high $12 \mathrm{~dB}$ as compared to the conventional antenna. Hence the antenna can operate well at the frequency $1.9 \mathrm{GHz}$ as is required for operating the CDMA devices. It may be concluded that this antenna shows high directivity with reduced size. Due to increase in the directivity, it may be possible that this antenna can work for CDMA devices up to some $\mathrm{Km}$ in a more efficient manner than the available conventional antennas. E-shaped antenna is designed and simulated over IE3D simulation software Ver. 14.2. The substrate used for the designing purpose has substrate thickness of $1.5748 \mathrm{~mm}$, dielectric constant 2.2 and loss tangent 0.0009 . The designed antenna structure provides good results in Table 2.

Table 2: Results of 3 simulation single antenna, $1 \times 2$ and 1x4 arrays antenna.

\begin{tabular}{|l|c|c|c|c|c|c|c|}
\hline Number of element & $\begin{array}{c}S_{11} \\
d B\end{array}$ & VSWR & $\begin{array}{c}\text { Gain } \\
d B\end{array}$ & $\begin{array}{c}\text { Directivity } \\
(d B)\end{array}$ & $\begin{array}{c}\text { Antenna } \\
\text { efficiency }\end{array}$ & $\begin{array}{c}\text { radiation } \\
\text { efficiency }\end{array}$ & $\begin{array}{c}\text { BW } \\
\text { efficiency }\end{array}$ \\
\hline Single at $1.9 \mathrm{GHz}$ & -25 & 1.15 & 5 & 7 & $63 \%$ & $88 \%$ & 8 \\
\hline $1 X 2$ array at $1.9 \mathrm{GHz}$ & -29 & 1.2 & 7.5 & 9 & $80 \%$ & $80 \%$ & $11 \%$ \\
\hline $1 X 4$ array at $1.9 \mathrm{GHz}$ & -13 & 1.5 & 11 & 12 & $77 \%$ & $80 \%$ & $16 \%$ \\
\hline
\end{tabular}

\section{REFERENCES}

[1] J. C. Liberti, T. S. Rappaport, "Smart Antennas for Wireless Communications: IS-95 and Third Generation CDMA Applications”, Prentice Hall, New Jersey, 1999.

[2] H. F. AbuTarboush, H. S. Al-Raweshidy, "A Connected E Shape and U-Shape Dual-Band Patch Antenna for Different Wireless Applications", the Second International EURASIP Workshop on RFID Technology, July, 2008.

[3] F. Yang, X. Zhang, Y. Rahmat-Samii, "Wide-band E-shaped patch antennas for wireless communications," IEEE Trans. Antennas Propagation, vol. 49, 2001, pp. 1094-1100

[4] Kazi Tofayel Ahmed, Md. Bellal Hossain, Md. Javed Hossain, "Designing a high band width Patch Antenna and comparison with the former Patch Antennas", Canadian Journal on Multimedia and Wireless Networks Vol. 2, No. 2, April 2011.

[5] Shackelford, A.K., Lee, K.F., and Luk, K.M.: "Design of small-size wide bandwidth microstrip-patch antennas”, IEEE Antennas Propag. Mag.,AP-45, (1), pp.75- 83, 2003.

[6] AngYu, XuexiaZhang, "A Method to Enhance the Bandwidth of Microstrip Antennas Using a Modified E shaped patch,” Radio and Wireless Conference, pp. 261 - 264, August 2003.

[7] G.Kumar\&K.P.Ray, “Broadband microstrip antennas”,Artech House,London, pp.11-14 2003,.

[8] D. M. Pozar, and D. H. Schaubert, “ Microstrip Antennas, the Analysis and Design of Microstrip Antennas and Arrays," IEEE Press, New York, USA, 1995.

[9] Balanis C. A., “Antenna Theory, Analysis and Design,” 3rd ed. Hoboken, NJ: Wiley, 2005.

[10] J. R. James and P. S. Hall, "Handbook of microstrip antennas", Peter Peregrinus, London, UK, 1985.

[11] MATLAB User Guide, The Math Works.

[12] Yikai Chen, Shiwen Yang, and Zaiping Nie, "Bandwidth enhancement method for low profile E-shaped microstrip patch antennas," IEEE transactions on antennas and propagation, vol. 58, no. 7, July 2010.

[13] J. Huang, "The finite ground plane effect on the Microstrip Antenna radiation pattern," IEEE Trans. Antennas Propagate, vol. AP-31, no. 7, pp. 649-653, 1983.

[14] Milligan, T. A.,"Modern Antenna Design”, John Wiley \& New Jersey, 2005. 
Antenna single Patch Antenna

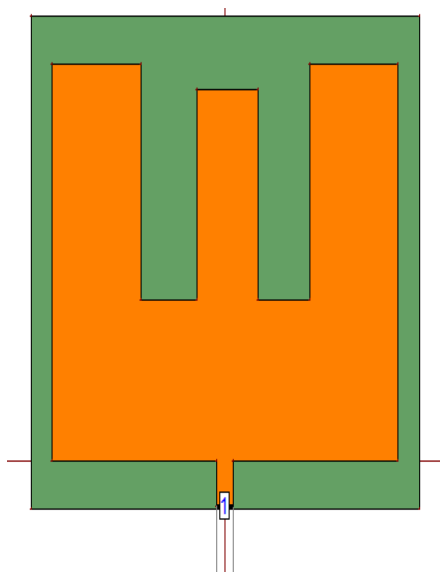

Antenna 1X2 Patch Antenna

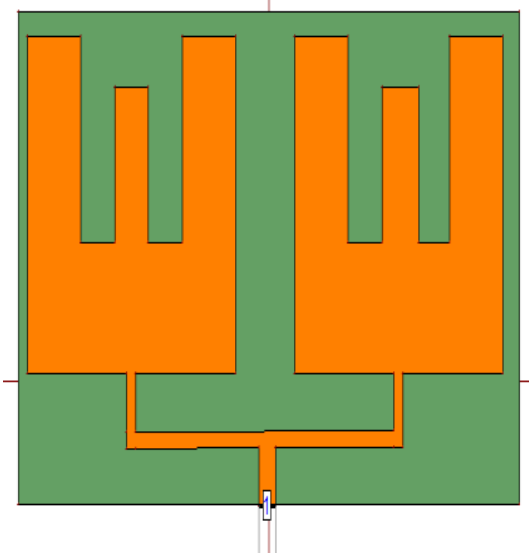

Antenna 1X4 Patch Antenna

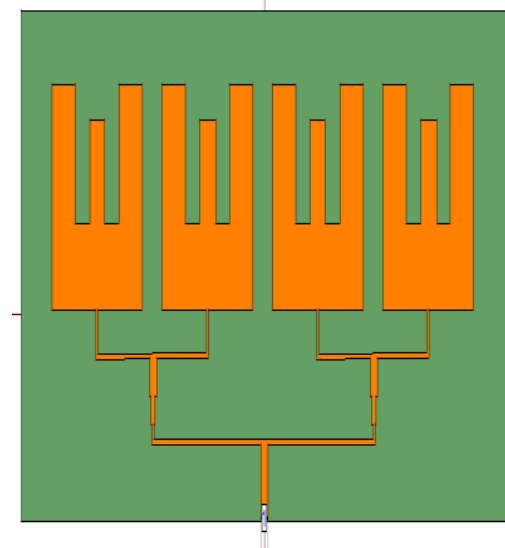

Fig. 1. Geometry of E-shaped microstrip antenna,

S.Parameters Display

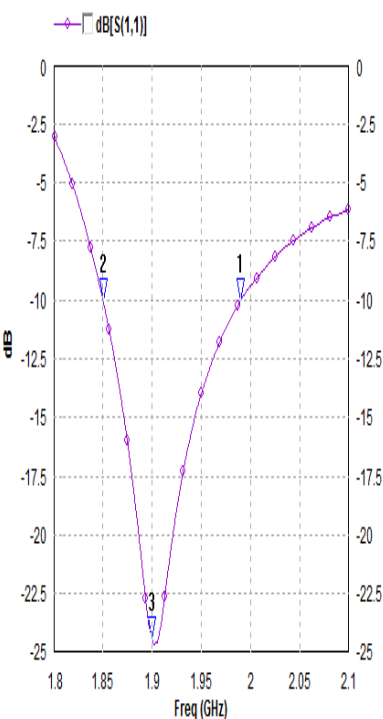

Fig 2 shows the return loss verses freq
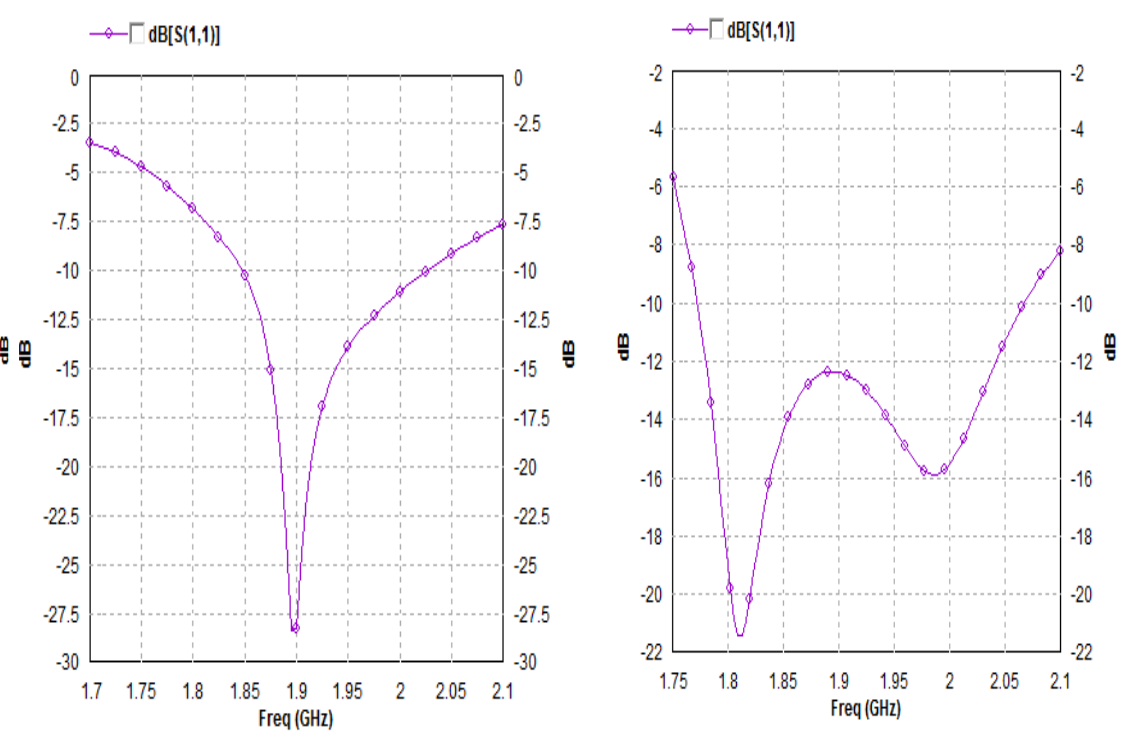

S.Parameters Display
ISWR Display

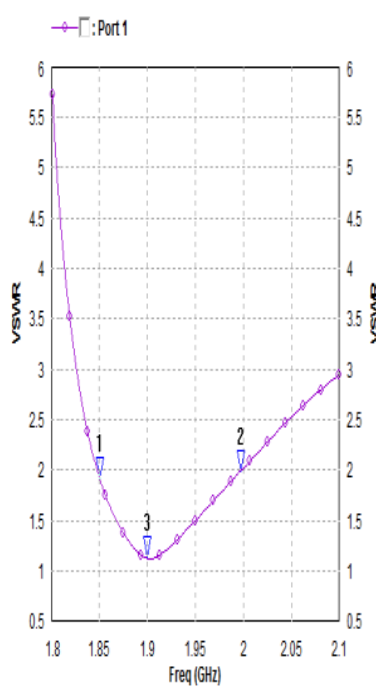

Fig. 3. Shows the simulated result of the VSWR $=1.1 ; 1.2 ; 1.6$ at $1.9 \mathrm{GHz}$

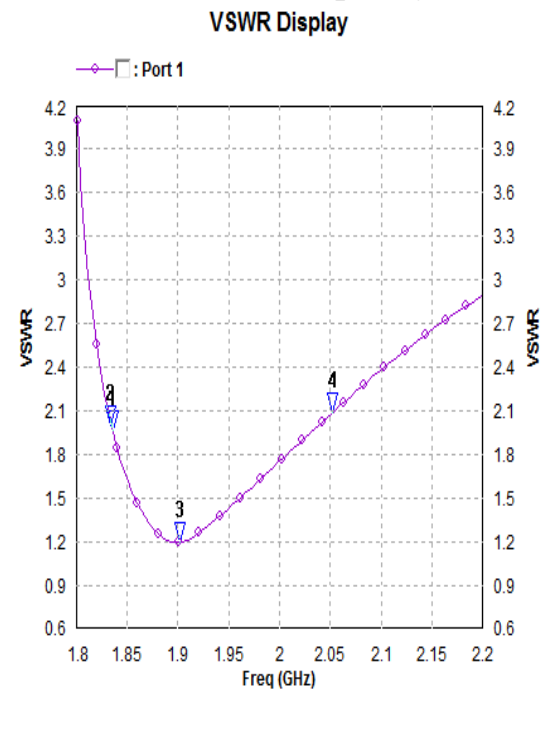

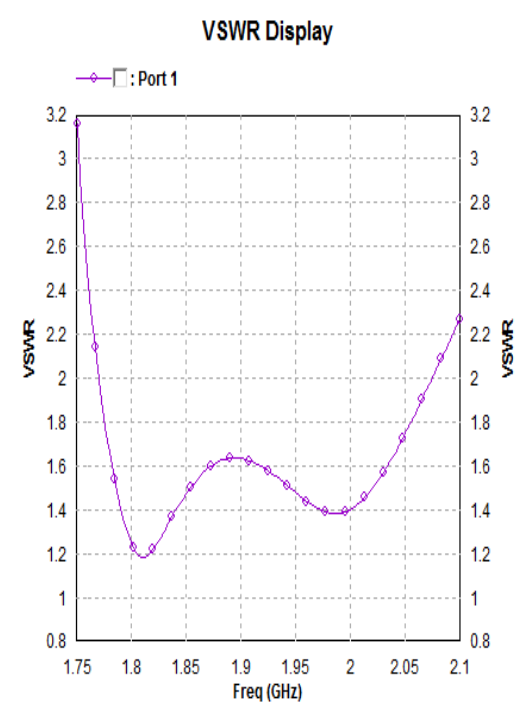


single Patch Antenna

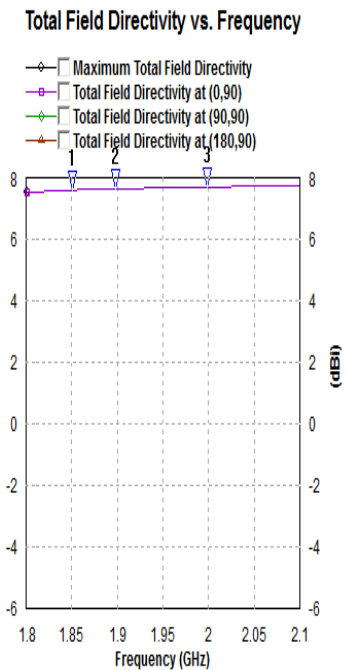

Antenna 1X2 Patch Antenna Total Field Directivity vs. Frequency

$\rightarrow-\Gamma$ Maximum Total Field Directivity

$\rightarrow-\Gamma$ Total Field Directivity at $(0,0)$

Totai Field Directivity at $(90,0)$

$\rightarrow-\Gamma$ Total Field Directivity at $(0,90)$

Total Field Directivity at $(90,90)$

$-{ }_{4} \Gamma$ Total Field Directivity at $(180,90)$

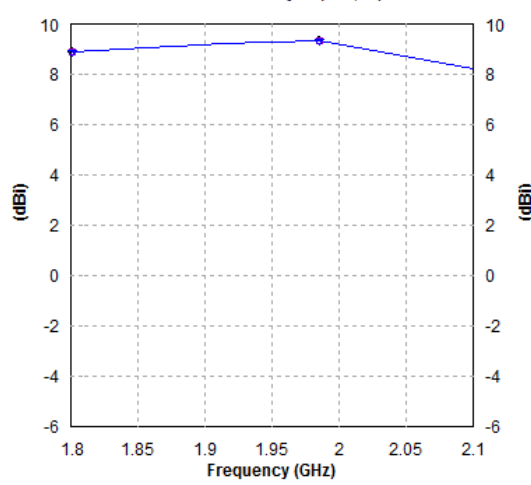

Antenna 1X4 Patch Antenna Total Field Directivity vs. Frequency

$\rightarrow-\Gamma$ Maximum Total Field Directivity $\square-\Gamma$ Total Field Directivity at $(0,0)$ Total Field Directivity at $(90,0)$ - Total Field Directivity at $(180,0)$ - Total Field Directivity at (0,90) $-\Gamma$ Total Field Directivity at $(180,90)$

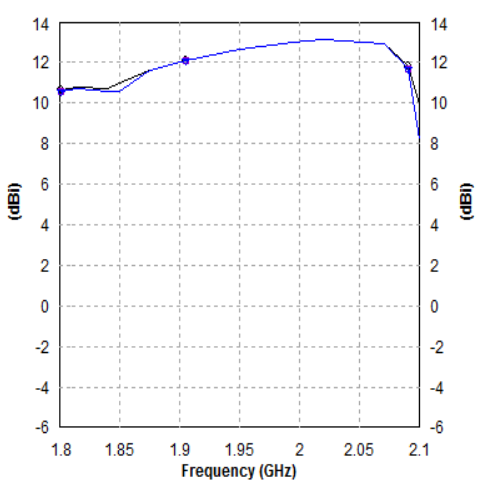

Fig. 4 Shows the simulated Directivity at various frequencies : $7 \mathrm{~dB} ; 9 \mathrm{~dB} ; 12 \mathrm{~dB}$ at $1.9 \mathrm{GHz}$
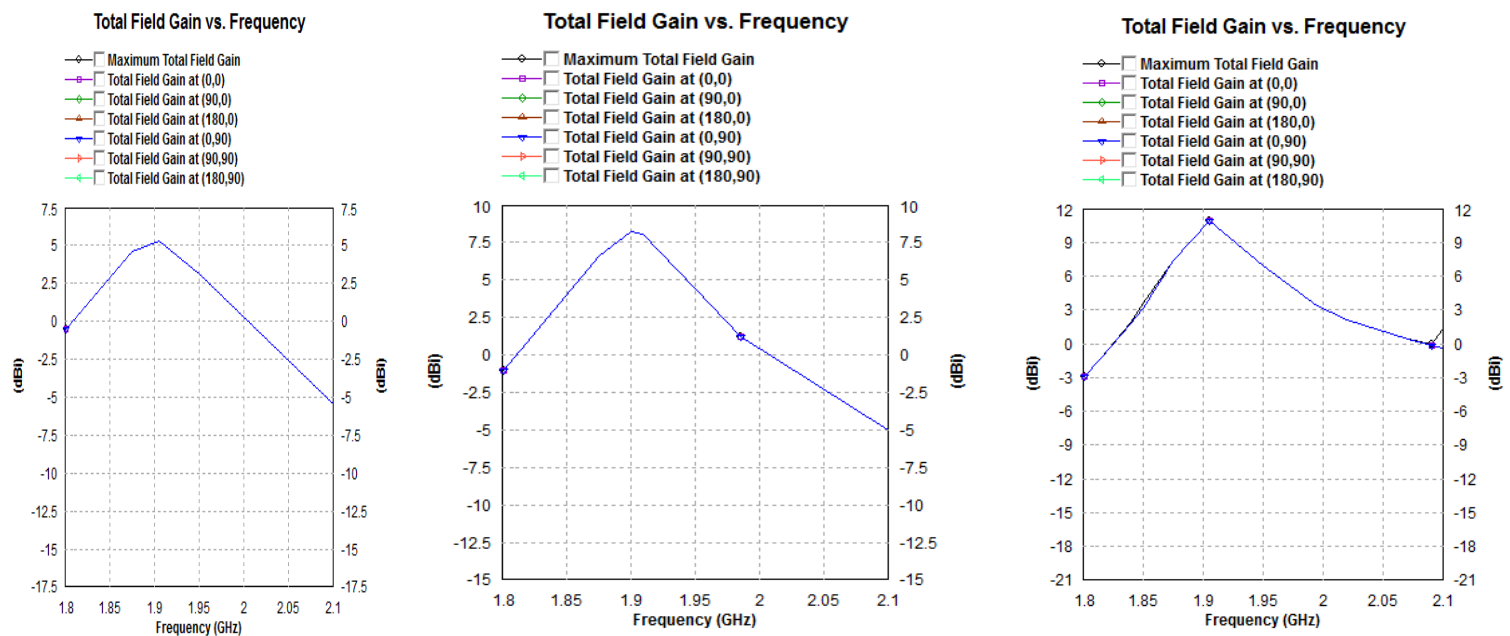

Fig. 5 Shows the simulated gain at various frequencies: $5 \mathrm{~dB} ; 7.5 \mathrm{~dB} ; 11 \mathrm{~dB}$ at $1.9 \mathrm{GHz}$

Efficiency Vs. Frequency

$$
\begin{aligned}
& \rightarrow-\ulcorner\text { Antenna Efficiency } \\
& \rightarrow-\Gamma \text { Radiation Efficiency }
\end{aligned}
$$

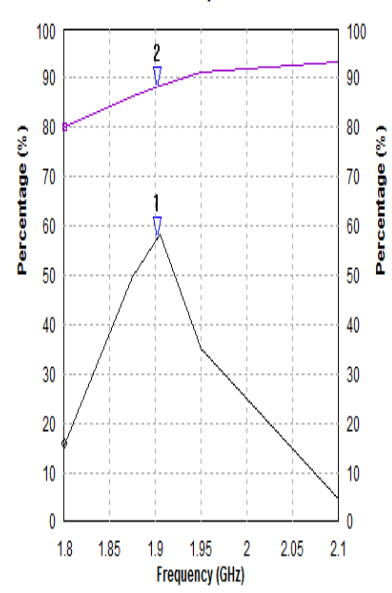

Efficiency Vs. Frequency

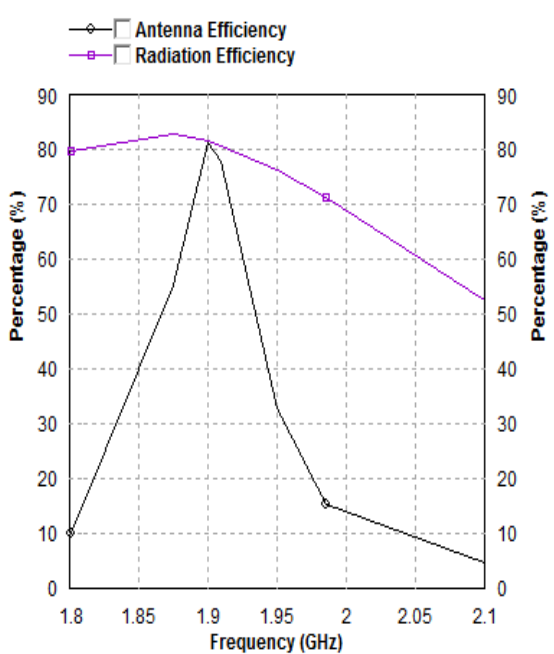

Efficiency Vs. Frequency

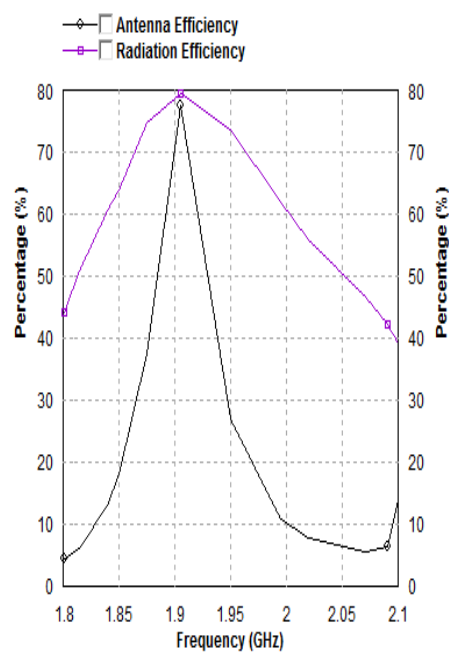

Fig 6 shows the antenna and radiation efficiency $=63,88 \% ; 80,80 \% ; 77,80 \%$ at $1.9 \mathrm{GHz}$ 

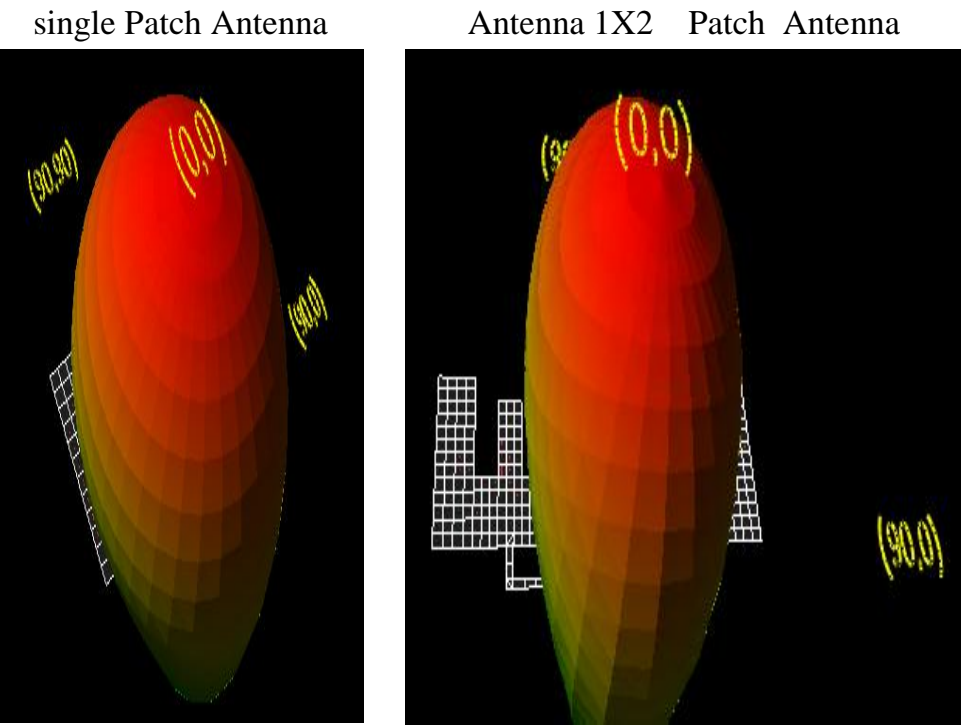

Antenna 1X4 Patch Antenna

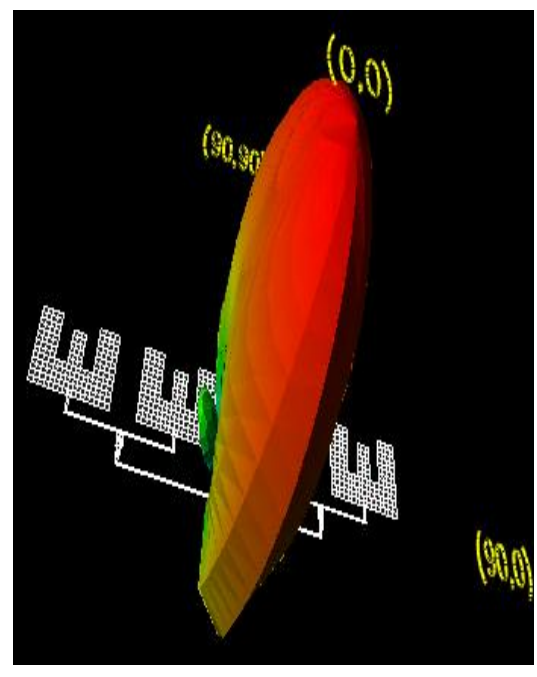

Fig. 7 shows the 3D radiation pattern view of proposed antenna 1; 2x1; 4x1.

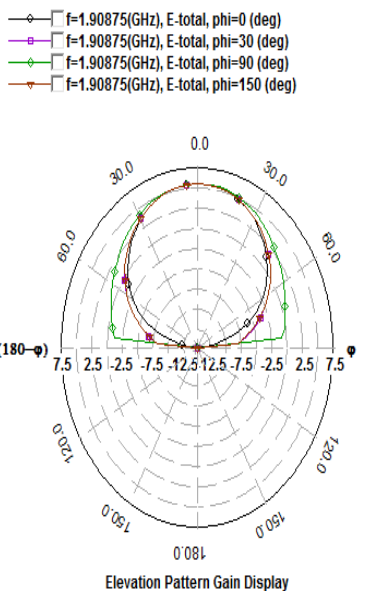

(dBi)
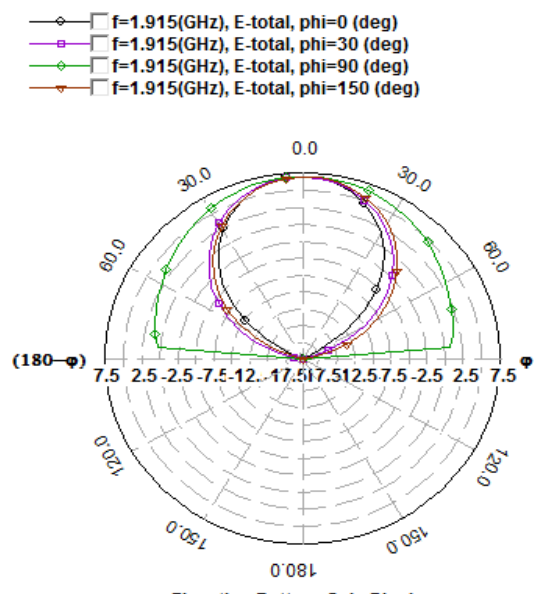

Elevation Pattern Gain Display

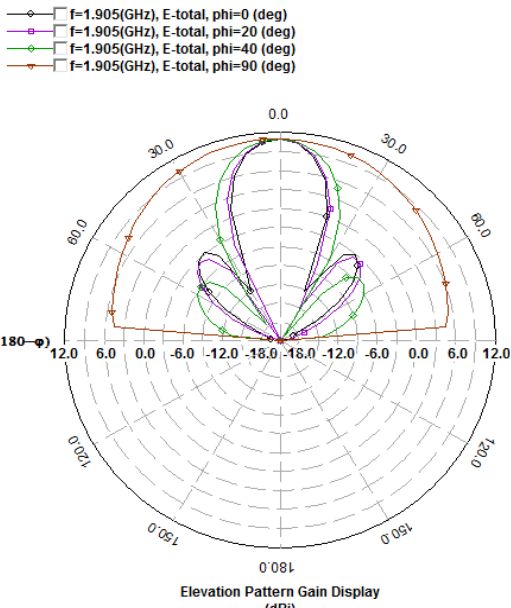

Elevation Pattern Gain Display

Fig. 8 shows the 2D radiation pattern view of proposed antenna 1; 2x1; 4x1. 